4. Hagiwara H, Shirakawa M, Nakayama T, Asai T, Nakayama M, Ito T, et al. The correlation between flow pattern during cardiopulmonary bypass and patency of the coronary artery bypass grafts. Kyobu Geka. $2005 ; 58: 519-23$
5. Morota T, Duhaylongsod FG, Burfeind WR, Huang T. Intraoperative evaluation of coronary anastomosis by transit-time ultrasonic flow measurement. Ann Thorac Surg. 2002;73:144650 .

\title{
Intermittent incomplete closure of Medtronic Advantage aortic valve leaflets causes unnecessary reoperation
}

\author{
Rune Haaverstad, MD, PhD, ${ }^{\mathrm{a}, \mathrm{c}}$ Nicola Vitale, MD, PhD, ${ }^{\mathrm{a}, \mathrm{c}}$ Arve Tromsdal, MD, ${ }^{\mathrm{a}, \mathrm{b}}$ Knut Hegbom, MD, ${ }^{\mathrm{b}}$ and \\ Asbjørn Karevold, MD, ${ }^{a}$ Trondheim, Norway
}

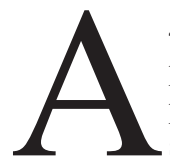

40-year-old man underwent isolated aortic valve replacement with a 23-mm Medtronic Advantage valve prosthesis (Medtronic, Minneapolis, Minn) for severe stenosis of a bicuspid aortic valve. The valve was implanted with pledgets by the non-everting suture technique and placed with the central orifice pointing in between the coronary ostia. The postoperative course was uneventful, and the patient was discharged on the sixth postoperative day. Control transthoracic echocardiograms were performed before discharge and 6 and 12 months after discharge, all of which showed a normal functioning prosthetic valve with a mean gradient of $12 \mathrm{~mm} \mathrm{Hg}$. The patient was in New York Heart Association functional class I and had resumed all his activities within the follow-up.

\section{Clinical Summary}

Two years after surgery and 1 year after the last echocardiogram, the patient had occasional transient memory losses and disturbed vision, which were consistent with thromboembolism because they were associated with a nontherapeutic international normalized ratio (INR) of 1.3. The patient underwent hemorrhoid surgery during the same period, which contributed to keep the INR level well below the desired 2.5 to 3.5 range. At the routine 2-year follow-up control (25.5 months after valve implantation), the patient was in good health and asymptomatic, despite a diastolic murmur of variable intensity on auscultation. The transthoracic echocardiogram revealed an intermittent and incomplete closure of the prosthetic leaflet, causing single-beat valve regurgitation of a degree varying from $1+$ to $3+$. The mean transvalvular

From the Departments of Cardiothoracic Surgery ${ }^{\mathrm{a}}$ and Cardiology, ${ }^{\mathrm{b}} \mathrm{St}$ Olavs University Hospital, Trondheim, Norway; and Institute of Circulation and Medical Imaging, ${ }^{\mathrm{c}}$ Norwegian University of Science and Technology, Trondheim, Norway.

Received for publication April 8, 2007; accepted for publication April 20, 2007.

Address for reprints: Rune Haaverstad, MD, PhD, Department of Cardiothoracic Surgery, St Olavs University Hospital, N 7018 Trondheim, Norway (E-mail: rune.haaverstad@ntnu.no).

J Thorac Cardiovasc Surg 2007;134:791-2

$0022-5223 / \$ 32.00$

Copyright $\odot 2007$ by The American Association for Thoracic Surgery doi:10.1016/j.jtcvs.2007.04.055 gradient was $14 \mathrm{~mm} \mathrm{Hg}$. The transesophageal echocardiogram confirmed these findings. The patient then underwent fluoroscopy; during the investigation the patient was in sinus rhythm, as usual, and no ectopic ventricular beats were recorded. Fluoroscopy showed intermittent incomplete closure of both valve leaflets (Figure 1). An incomplete closure of the anterior leaflet occurred approximately every 10 beats; this appeared to create a minor gap between the inner side of the ring and the leaflet edge, most likely causing a trivial regurgitation (Figure $1, A$ ). In addition, a closure delay of the posterior leaflet was caught just once during film recording. In this position, it was discovered that the posterior leaflet stood open at approximately 90 degrees from the valve ring while the anterior leaflet was closed (Figure 1, $B$ ). We believe this phenomenon is responsible for the $3+$ regurgitation noted on the echocardiograms.

On the basis of the patient history and investigations, the cause of the prosthetic malfunction was assumed to be an obstruction limiting leaflet excursions; therefore, the patient underwent reoperation the following day. During surgical exploration, no pannus or thrombus was found on or around the valve; the valve was normal in appearance and function, and both leaflets had free movement. No subvalvular tissue was seen bulging into the hinge mechanism, and the valve was left in place.

The postoperative course was uneventful, and the patient was discharged. At the last control in March 2007, the patient was still in New York Heart Association class I and totally asymptomatic; his INR level was stable between 2.5 and 3.5. The transthoracic echocardiography showed a mean gradient of $12 \mathrm{~mm} \mathrm{Hg}$ and an intermittent incomplete closure of 1 leaflet in approximately $15 \%$ of the strokes, determining transient, single-beat, trivial-to-mild regurgitation.

\section{Discussion}

This case report is in line with previous articles from Munich in which a total of 7 cases of intermittent regurgitation of a Medtronic Advantage aortic valve were observed. ${ }^{1,2}$ Unfortunately, in our case there were several confounding factors that led us to believe the incomplete closure was caused by a thrombotic obstruction, and the patient underwent reoperation. First, there was a transient ischemic attack associated with a prolonged period of a low INR level, which was then followed by concomitant recent hemorrhoid 


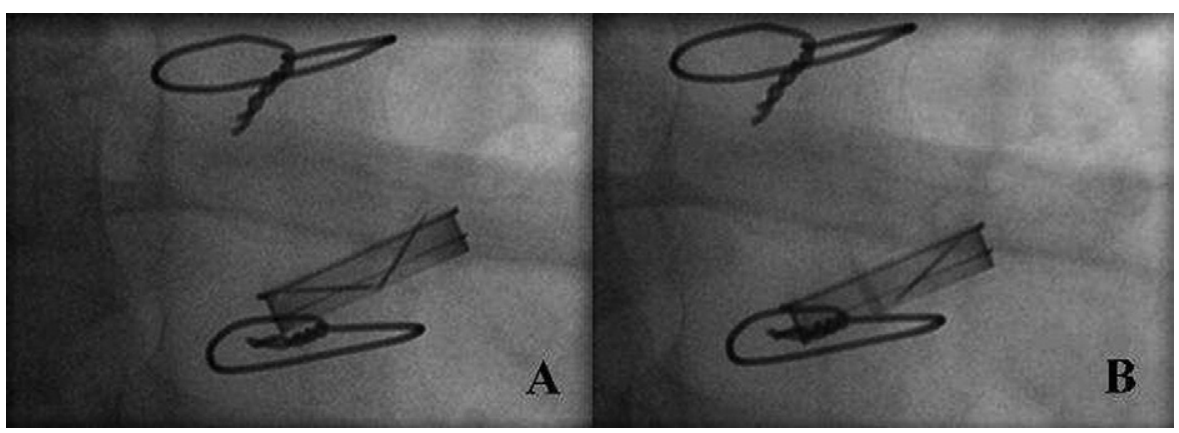

Figure 1. Fluoroscopic scan using of the Medtronic Advantage 23-mm aortic valve (Medtronic, Minneapolis, Minn). Incomplete closure of the anterior leaflet, leaving a minor gap between the ring and the leaflet edge (A). Delayed closure of the posterior leaflet standing open at approximately 90 degrees from the ring $(B)$.

surgery. Second, the initial report or information on this phenomenon was not available yet. ${ }^{1}$

Understanding the mechanism underlying this phenomenon is not an easy task because no hints other than its visualization are available to the investigators. Recently, Medtronic created an in vitro incomplete closure in a single size 23 Advantage valve using a flow testing system that was specifically developed to study this phenomenon. Creation of this incomplete closure required horizontal orientation of the valve so gravity maximized asynchronous closure and worked against the closure of the second leaflet. In vitro creation of an incomplete closure requires a very low flow. When the valve fails to close completely the first leaflet to close rotates past the center of the valve as intended by the design. The second-to-close leaflet contacts the straight edge of the first-toclose leaflet, but under these very low flow conditions it does not exert sufficient force to push the first leaflet back toward the center of the valve. The second-to-close leaflet sits in a partially open position contacting the first-to-close leaflet along the straight edge of the leaflets. By applying this model, Medtronic was able to replicate incomplete closure in a number of size 23 valves (personal communication, Andrew Campbell, $\mathrm{PhD}$, Medtronic Inc, 2006).

In our case, the valve was oriented in the same fashion as are all bileaflet valves implanted at our institution. Our case had some similarities with the Munich series, as the incomplete closure of the anterior leaflet generated a trivial regurgitation. ${ }^{1,2}$ On the other hand, it also presented a delayed closure of the posterior leaflet, causing a $3+$ regurgitation. The frequency of this latter phenomenon is difficult to assess because of its rare occurrence, which may require a long period of observation. With the aim of researching the causes of this phenomenon, we came across an experimental study by Grattan and Thulin ${ }^{3}$ that demonstrated that external forces applied to the St Jude Master valve ring (St Jude Medical Inc, St Paul, Minn) may cause leaflet malfunction by exerting axial pressure on the ring. This may happen after aortic valve replacement when the hinge mechanism within the pivot guard is placed directly against the subannular tissues of the left ventricular outflow tract. ${ }^{3}$ In this position, the hinge mechanism will be subjected to the static compression of the outflow tract tissues and the systolic compressive forces. ${ }^{3}$ We wonder whether this behavior may have played a role in our case. Medtronic tests every Advantage heart valve, verifying the force required to inhibit leaflet motion is greater than the force reported by Grattan and
Thulin for the St Jude valve (personal communication, Andrew Campbell, PhD, Medtronic Inc, 2006). Little is known about the actual force applied to the housing in the aortic annulus, and therefore this possibility cannot be excluded for either the Advantage or the St Jude valve.

On clinical grounds, our patient, as well as those in Munich, is asymptomatic and the sudden decrease of diastolic pressure recorded concomitantly with the incomplete valve closure ${ }^{1}$ does not seem to impair hemodynamic measurements. Moreover, the worldwide follow-up study, ${ }^{4}$ as well as our own, ${ }^{5}$ reported excellent outcomes in line with those of other long-established bileaflet valves in their early clinical stages. So far, more than 8000 Advantage heart valves have been implanted in patients worldwide (personal communication, Andrew Campbell, PhD, Medtronic Inc, 2006).

It is important that surgeons implanting or intending to implant Medtronic Advantage aortic valve prostheses are aware of this phenomenon to avoid the risk of unnecessary surgery. The rare occurrence of intermittent regurgitation under a narrow set of conditions does not seem to present any risk to patients so far and may be present in other valve designs that have not yet been studied as thoroughly. Nonetheless, a longer follow-up study of intermittent incomplete closure is mandatory to confirm the initial speculation as to the benign nature of this phenomenon.

\section{References}

1. Eichinger WB, Wagner I, Bleiziffer S, von Canal F, Lange R. Occasional single-beat regurgitation observed with the new Medtronic ADVANTAGE bileaflet heart valve. J Thorac Cardiovasc Surg. 2006; 131:730-1

2. Eichinger WB, Wagner I, Bleiziffer S, von Canal F, Gunzinger R, Ruzicka DJ, et al. Occasional single-beat regurgitation observed with the Medtronic Advantage bileaflet heart valve. Ann Thorac Cardiovasc Surg. 2006;82:537-41.

3. Grattan MT, Thulin LI. Leaflet arrest in St Jude Medical and CarboMedics valves: an experimental study. Eur J Cardiothorac Surg. 2004;25:953-7.

4. Köerfer R, Svennevig JL, Mohr FW, Leguerrier A, Menicanti L, Olsen PS, et al. The worldwide mid-term experience with the Medtronic Advantage bileaflet mechanical heart valve. J Heart Valve Dis. 2006; 15:404-13.

5. Haaverstad R, Vitale N, Karevold A, Cappabianca G, Tromsdal A, Olsen PS, et al. Clinical and echocardiographic assessment of the Medtronic ADVANTAGE aortic valve prosthesis: the Scandinavian multicentre, prospective study. Heart. 2007;93:500-5. 